\title{
Judging Japan's FDI: The verdict from a dartboard model*
}

\author{
Keith Head ${ }^{\dagger} \quad$ John Ries ${ }^{\ddagger}$
}

March 8, 2004

\section{Introduction}

During the 1980s, Japanese multinationals emerged as one of the top sources of overseas investment. However, Japan - the world's second largest economy - continued to host only meagre amounts of foreign direct investment (FDI). Was Japan an overachiever for outward FDI and an underachiever for inward FDI?

An assessment of whether a country makes "too many" or "too few" international transactions requires a benchmark of cross-border activity derived from sound theory. For example, there is strong sentiment that Japan imports too few manufactures. The predictions of the Heckscher-Ohlin theory and the gravity model of international trade have been used to assess this contention. With regard to foreign direct investment (FDI), Japanese is recognized as a large source country but has been under considerable pressure to increase is inward FDI based on the premise that it is too low.

This paper develops a simple model of FDI that generates predictions of a country's share of world FDI based on its capital stock, human capital, and and its size-weighted proximity to potential host and source countries. We use the analogy of darts as management teams targeting production units, whose international distribution corresponds to areas on a dartboard. After compiling a data set covering 130 countries from 1980-2002, we use the dartboard model construct benchmark predictions for FDI. This allows use to assess how well actual FDI patterns conform to the model and examine how Japan's FDI performance relative to the benchmark has evolved over time.

Studies of Japan's trade pattern illustrate the value of judging performance through lens of a theoretical benchmark. For Japanese imports, some have argued that the Japanese market is closed because its manufacturing imports to GDP ratio is lower than other industrialized countries. However, this view has not held up once theory is applied. Saxonhouse (1993) estimates a theoretical model that refutes this contention by showing that Japan's distinctive trade structure can be explained by its pattern of factor endowments. More recently, Harrigan (2003) uses a gravity model to show that Japan's

* Totally Preliminary and Incomplete. We thank our discussant Fuku Kimura in advance for his astute remarks.

†Sauder School of Business, University of British Columbia, Email:keith.head@ubc.ca

${ }^{\ddagger}$ Sauder School of Business, University of British Columbia, Email:john.ries@ubc.ca 
"normalized" (for market size) imports from the U.S. are higher than U.S. imports from Japan. Head, Ries and Spencer (2004, forthcoming) apply a model incorporating the relationship-specific investment of input suppliers to U.S. auto part trade and find Japan imports about what the model predicts.

Critics point to Japan's low level of inward FDI relative to GDP as evidence of too little investment in Japan (see Fukao and Amano, 2003). Other's have used a gravity model of FDI to establish this position. Eaton and Tamura (1994) find that Japan is more open to U.S. exports, but less open to FDI (foreign direct investment) than most countries in Western Europe. Eaton and Tamura (1996) confirm this finding using a gravity-type specification generated from a model technological adoption via either exports or FDI.

This paper contributes to the literature by establishing theoretical underpinnings for a gravity-like model of FDI. The next section discusses existing models of FDI and identifies their limitations for assessing FDI performance in an international perspective. The following section develops our model that posits FDI as an outcome of management teams making bids on capital. Section 4 details the data we use, explains why a model of acquisitions is appropriate for modelling FDI, and discusses issues concerning the international distribution of human capital. Using both figures and regressions, section 5 shows how well our model fits the data and Japan's inward and outward FDI position relative to the theoretical predictions and different points in time. The final section summarizes the results an suggests directions for suture research.

\section{Existing Models of FDI}

Until 1984, the academic study of FDI consisted mainly of verbal analytical frameworks constructed by management professors. Elhanan Helpman (1984) and James Markusen (1984) launched the modern formal economics literature on foreign direct investment (FDI). Helpman (1984) viewed FDI through the lens of factor proportions theory and emphasized the separation of the firm into two activities, one appropriate for skillabundant countries and the other best carried out in skill-scarce countries. Markusen (1984) modelled FDI as way that firms could achieve multi-plant economies while avoiding trade costs. In the literature that followed, the Helpman (1984) and Markusen (1984) approaches came to be known vertical and horizontal FDI. In his monograph summarizing the FDI literature of the last decade, Markusen (2002, p. 5) defines vertical FDI as investments that "geographically fragment the production process by stages of production" and horizontal FDI as "foreign production of products and services roughly similar to those that the firm produces for its own market."

Markusen (2002) also develops and promotes his "knowledge-capital" model that integrates both vertical and horizontal motives for FDI. Since there is abundant anecdotal evidence of both motives in practice, the knowledge capital model seems eminently sensible. But the realism associated with considering both motives in a general equilibrium setting with free entry does come at a cost. The knowledge capital model comprises over 40 equations in which there are inequalities with associated non-negative variables (chiefly, the numbers of various types of firms). It can only be solved numerically using Rutherford's mixed complementarity problem solving program, GAMS. Eaton and 
Tamura (1996) also must use simulations to gernate predictions about the level of FDI in their two-country, general equilibrium model of FDI.

Almost everyone is sympathetic towards Albert Einstein's famous dictum that "Things should be made as simple as possible, but not any simpler." One practical issue is when do particular complications of a simple model justify themselves through greater insight?

A second issue is that even complex models like the knowledge capital model and the Eaton and Tamura model, must make drastic simplifications. Both consider only two countries. The world has 100 times as many. This leads to two problems. First, do the two-country predictions extend to the $n$ country case? Second, even if they do extend, while they useful for predicting patterns for a particular source country relative to different host countries, can they be used, for example, to determine what Japan's overall FDI levels should be relative to the United States? To identify a concrete issue regarding extension to higher dimensions, the knowledge capital model predicts that horizontal FDI will be high when the two countries have similar factor endowments. This makes sense in the case of, say, Canada and the United States. However, one presumably does not see high horizontal FDI in the case of less developed countries with similar factor endowments.

Markusen's theory focuses on a firm that deploys the same "blueprints" at multiple production sites. The approach does not explicitly consider multinationals that expand by acquiring existing firms with their own established blueprints. The data suggest that the majority of FDI in the world takes the form of acquisitions.

\section{The Dartboard Model of FDI}

Here we develop a model that is very simple: it can be reduced to a single equation. We explicitly consider the acquisition decision and we also allow for an arbitrary number of different sized countries. That being said the simplest version of our model could be called "aggressively unrealistic." We see it as providing a handy benchmark for evaluating FDI levels. It also offers a starting point for richer characterizations of FDI.

The model takes its inspiration from the notion in corporate finance of the market for corporate control, described by Jensen and Ruback (1983) as "an arena in which managerial teams compete for the rights to manage corporate resources." The name "dartboard" derives from the Ellison and Glaeser approach to quantifying geographic concentration of industries. In our case, darts correspond to investors whereas areas on the dart board correspond to the assets available in each country. The mechanics of the model draw on Deardorff's (1998) derivation of a gravity-like equation for bilateral "frictionless" trade.

Each country $j$ has $N_{i}$ controllable corporate production units. These could correspond to firms or to the amount of equity an investor would have to hold in a firm to gain a seat on the board of directors. Since the IMF defines FDI based on a 10\% rule, the units might be tenths of firms.

Each country $i$ has $M_{i}$ management teams that bid to control the corporate production units. There are $M_{w}=\sum_{i} M_{i}$ management teams worldwide.

The management teams bids on each of the $N_{w}=\sum_{j} N_{j}$ available units. The average winning bid for a unit in country $j$ is $V_{j}$. Therefore, the aggregate stock of capital is 
$K_{j}=V_{j} N_{j}$. The probability a given unit in $j$ is acquired by particular bidder from $i$ will be denoted $\pi_{i j}$. Defining $F_{i j}$ as source country $i$ 's FDI stock in host country $j$,

$$
F_{i j}=\pi_{i j} K_{j}
$$

\section{1 "Frictionless" FDI}

In the simplest version of the model, each bidding management team is symmetric. While they have different valuations for particular controllable units, their valuations are independent and identically distributed. In auction theory terminology, we are in the "independent private values" paradigm. Each bidder has an equal probability of winning equal to $1 / M_{w}$. Consequently, the combined probability of any team from country $i$ winning a particular unit in country $j$ is $\pi_{i j}=M_{i} / M_{w}$. Substitution yields a simple equation for bilateral FDI:

$$
F_{i j}=\frac{M_{i} K_{j}}{M_{w}}
$$

Summing over all foreign destination countries $j$ we obtain an equation for outward investment of country $i$ :

$$
F_{i w}=\sum_{j \neq i} F_{i j}=\left(M_{i} / M_{w}\right) \sum_{j \neq i} K_{j}=\left(M_{i} / M_{w}\right)\left(K_{w}-K_{i}\right)=\left(M_{i} / M_{w}\right) K_{w}\left(1-K_{i} / K_{w}\right) .
$$

A destination country's aggregate inward FDI can be obtained by summing over foreign source countries:

$$
F_{w j}=\sum_{i \neq j} F_{i j}=\left(K_{j} / M_{w}\right) \sum_{j \neq i} K_{j}=\left(K_{j} / M_{w}\right)\left(M_{w}-M_{j}\right)=K_{j}\left(1-M_{j} / M_{w}\right) .
$$

Worldwide direct investment stocks equal the sum of either inward or outward stocks.

$$
F_{w w}=\sum_{i} F_{i w}=\sum_{j} F_{w j}=K_{w}\left(1-\sum_{j}\left(M_{i} / M_{w}\right)\left(K_{i} / K_{w}\right)\right) .
$$

We now introduce lower case notation to denote country-level variables that are express as shares of their worldwide values. Thus we let country $i$ 's share of management teams by $m_{i}=M_{i} / M_{w}$, country $j$ 's share of capital be $k_{j}=K_{j} / K_{w}$. FDI shares are denoted $f_{j}^{I}=F_{w j} / F_{w w}$ for inward stocks and $f_{i}^{O}=F_{i w} / F_{w w}$ for outward stocks. Using this notation we show the two equations of the dartboard model of FDI:

$$
\begin{aligned}
f_{i}^{O} & =m_{i} \frac{1-k_{i}}{1-\sum_{j} m_{j} k_{j}} \\
f_{j}^{I} & =k_{j} \frac{1-m_{j}}{1-\sum_{i} m_{i} k_{i}}
\end{aligned}
$$

A special case is where $m_{i}=k_{i}$, that is each country's share of management teams matches its share of controllable production units. In that case we have

$$
f_{i}^{O}=f_{j}^{I}=k_{i} \frac{1-k_{i}}{1-H}
$$

where $H=\sum_{j} k_{j}^{2}$ is the Herfindahl concentration index for the worldwide distribution of capital. 


\subsection{Remote Control Costs}

The model has so far deliberately excluded all sorts of frictions that influence the pattern of FDI. This simplification yields a remarkably compact expression for FDI stocks. However there are good reasons to believe that teams will be more likely to obtain control of production units if they are relatively nearby. This is because the prospective bidder recognizes the high costs of monitoring production units that are long distances away from the management team's head office. Without adequate monitoring, there would be high agency costs. Management teams anticipate these costs and reduce their bids for faraway units accordingly.

We use discrete choice theory to derive $\pi_{i j}$ as follows. First, let $V_{h i j}^{*}$ be the unobserved variable corresponding to bidder $h$ from country $i$ 's valuation of a representative controllable unit in $j$. The base valuation in a frictionless world is $\epsilon_{h i j}$. Due to the cost of controlling an asset from a remote head office, the team reduces its bid by an amount equal to $\theta \ln d_{i j}$, where $d_{i j}$ measures distance between source and host country. Assume that $\epsilon_{h i j}$ is distributed Gumbe $\prod^{1}$ with cumulative distribution function given by

$$
\operatorname{CDF}\left(\epsilon_{h i j}\right)=\exp \left[-\exp \left(-\epsilon_{h i j}\right)\right] .
$$

The probability that a given team $h$ from $i$ obtains a draw $\epsilon_{h i j}$ on its valuation of a target in $j$ that is large enough to make it the highest bidder is given by the multinomial logit formula:

$$
\frac{\exp \left(-\theta \ln d_{i j}\right)}{\sum_{\ell} \exp \left(-\theta \ln d_{\ell j}\right)},
$$

where the $\ell$ indexes all the competing bidders for the representative unit in $j$. Since all bidders from a given country are assumed to be symmetric we obtain the probability of any bidder from $i$ winning the asset in $j$ as

$$
\pi_{i j}=\frac{M_{i} / d_{i j}^{\theta}}{\sum_{\ell} M_{\ell} / d_{\ell j}^{\theta}},
$$

where $\ell$ now indexes the countries where bidding management teams are headquartered. Note that management teams from country $j$ are included in the set of bidders for country $j$ production units.

We introduce $P_{j}^{I}=\sum_{\ell} M_{\ell} / d_{\ell j}^{\theta}$ as measure of the "bid potential" for a representative unit in country $j$. Bid potential is an index of proximity to bidding teams. When $\theta=1$, bid potential takes the same functional form as the market potential term used by geographers. We can now express bilateral FDI stocks as

$$
F_{i j}=\frac{M_{i} K_{j}}{P_{j}^{I} d_{i j}^{\theta}} .
$$

Summing across hosts for a given source country, we obtain

$$
F_{i w}=\sum_{j \neq i} F_{i j}=M_{i} \sum_{j \neq i} \frac{K_{j}}{P_{j}^{I} d_{i j}^{\theta}} .
$$

\footnotetext{
${ }^{1}$ This distribution is also known as the Type I extreme value, double exponential, and log-Weibull. It can be formulated with a scale parameter determining the standard deviation of bids. However this parameter could not be identified separately from $\theta$.
} 
We use $P_{i}^{O}=\sum_{j \neq i}\left(K_{j} / P_{j}^{I}\right) d_{i j}^{-\theta}$ to measure "target potential" for outward investors from country $i$. Using this notation we have $F_{i w}=M_{i} P_{i}^{O}$. Summing over all sources delivers worldwide outward investment of

$$
\begin{gathered}
F_{w w}=\sum_{i} M_{i} P_{i}^{O} \\
f_{i}^{I}=F_{i w} / F_{w w}=\frac{m_{i} P_{i}^{O}}{\sum_{\ell} m_{\ell} P_{\ell}^{O}} .
\end{gathered}
$$

Countries with relatively large numbers of bidding management teams and target potential should account for a large share of the world's outward investment.

\section{Data}

The model requires data on FDI, physical capital, a measure of management teams, and distance between countries. As described below, we collect data for various sources to obtain a panel data set for about 130 countries from 1980-2002.

Foreign direct investment occurs when investors in one country establish or acquire a significant portion of the assets in an enterprise in another country. In principle "significant" means enough to gain an active voice in the management of the enterprise. In IMF practice "significant" means more than 10\%. Thus, FDI involves cross-border ownership and some degree of control.

We obtain data on FDI flows and stocks from United Nations Conference of Transnational Corporations (UNCTAD). World inward and outward FDI data is available but they do not provide information on a bilateral basis. The OECD has some data on bilateral FDI but it is very incomplete.

FDI comprises three components: equity, retain earnings, and loans. Equity and retained earnings depends on the equity stake of the foreign parent whereas loans measure the indebtedness of affiliates to parent. For the most part, the flows of these components are reported in the balance of payments accounts as compiled by the International Monetary Funds. Since the balance of payments measure cross-border transfers, these accounts do not capture changes in the equity position of parent in foreign affiliates financed in local capital markets. However, the accounts do record changes in retained earnings. Although, no cross-border capital flow actually occurs, the accounts assume earnings are repatriated (a payment for financial services) and then sent back to the affiliate (an increase in direct investment). To the extent possible, UNCTAD basis its FDI flow and stock data on information collected from national sources. Stocks represent FDI on a book or historical basis. The time series on outward stock is influenced by changes in the source of the data. For example, Japan's outward FDI stock reported in the 2003 World Investment Report is based on IMF data for 1980-1996 and national sources from 1996-2002. Inconsistencies in the time series data can also arise when IMF revises how it defines and reports information on direct investment.

Merger and acquisition (M\&A) data is also recorded by UNCTAD and represents transaction amounts at the time of closure of the deal. Thus, M\&A transaction data deviates from bilateral FDI flows for three reasons. First, they include capital raised domestically and internationally (i.e., the amounts are not restricted to capital financed 


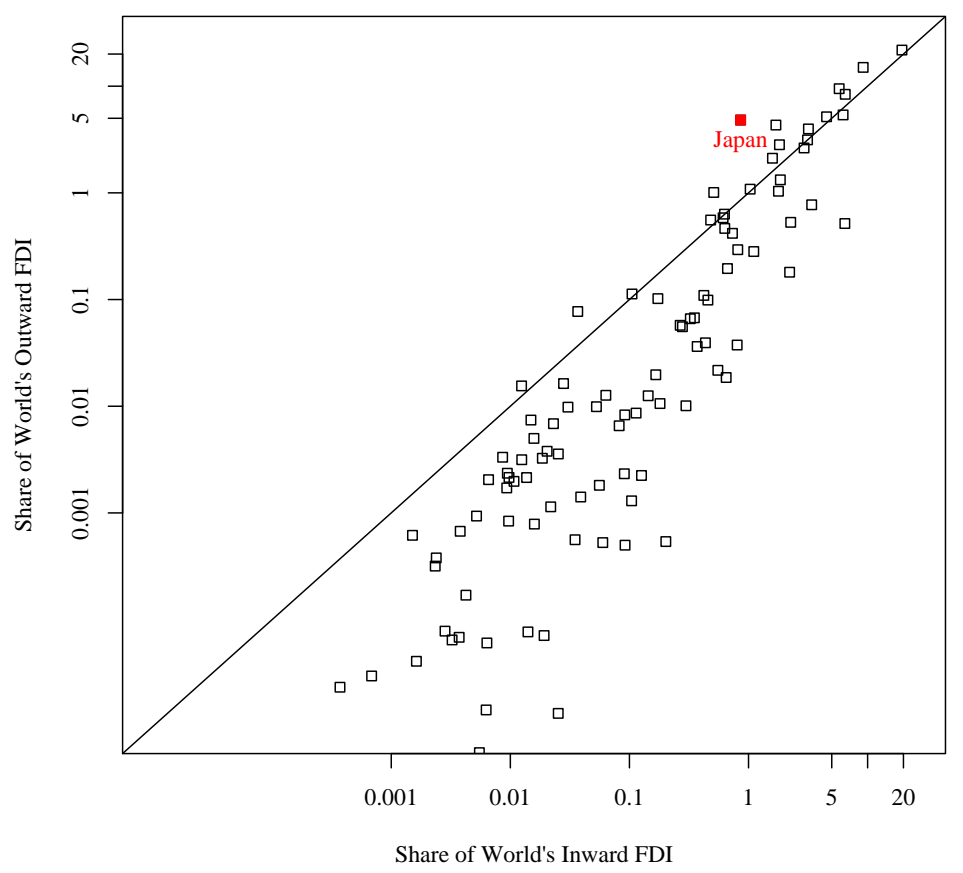

Figure 1: The relationship between inward and outward FDI in 2002

by the home country). Second, the M\&A data reflects gross investment and does not deduct any disinvestment. Third, the UNCTAD data records M\&A capital as being paid out in a single year even though this is not necessarily the case.

For our present analysis, we choose to focus on FDI stocks rather than flows or M\&As for a couple of reasons. M\&A and FDI flow data are highly correlated because M\&As account for a significant portion of FDI (EVIDENCE ABOUT THIS TO BE ADDED).

Figure 1 shows country's shares of world outward FDI relative to shares of world inward FDI on a log scale using 2002 stocks. The 45 degree line is represents the two shares being equal. The figure reveals that many countries have low levels of outward FDI relative to their levels of inward FDI. Later we will see that these are less developed countries. Japan has a higher outward share than inward share. Figure 2 reveals where Japan ranks in terms of stocks and flows on FDI over time.

Capital stock data for our period of interest is problematic. The World Bank provides capital stock data for the 1980-1990 period with country coverage declining over time. To obtain capital stocks for the later periods we used information of gross fixed capital expenditures. In the first year where World Bank capital stock data was unavailable, we calculated stock for that year by depreciating the capital stock by $7 \%$ and adding gross fixed capital expenditures. This procedure allowed us to compute capital stocks whenever capital stock information was available. We also experimented with using GNI as a proxy for capital, a method that is justified if capital is proportional to GNI. Figure 3 shows that capital shares closely match income shares.

We try a variety of ways to measure a country's share of management teams, $M$ in 


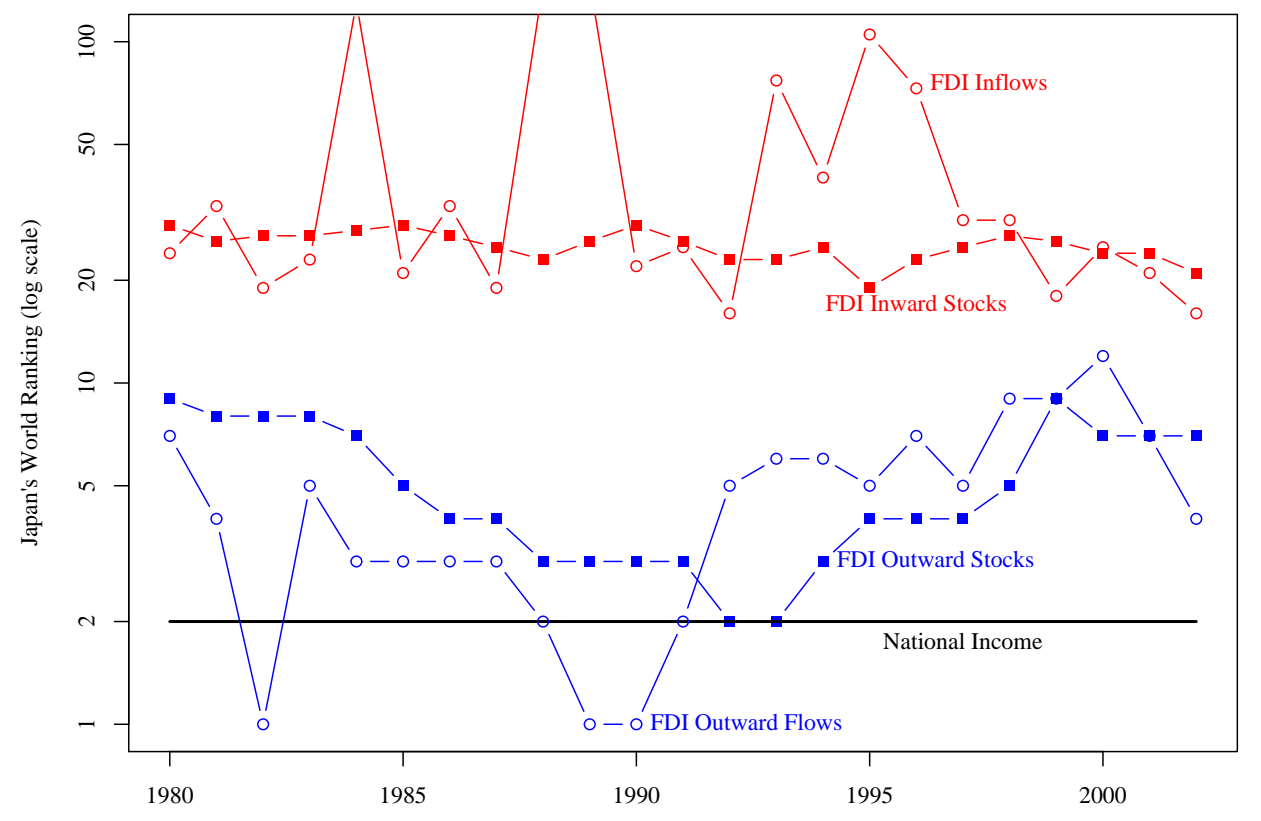

Figure 2: Japan's ranking as host and source for FDI

the model. The crudest (but easiest to construct) measure is assumes teams are proportional the national income. Supposing that management teams are strongly related to highly educated workers, we also assume $M$ is proportional to the number of people with completed post-secondary education that we refer to as HIED. We also measure human capital following the method of Hall and Jones (1999), where human capital is constructed from Mincer regression returns to education (HCAP). The problem that arises with both of these measures is that the high income countries emerge as human capital scarce countries, whereas China and India are human capital abundant! This can be seen in Figure 4 that plots shares of workers with post-secondary education against shares of GNI (representing shares of all factors). Countries above (below) the 45 degree line are human capital abundant (scares). The figure also indicates by shading countries that are near to the U.S. in per capita income. We see these high per capita income countries tend to be capital scarce.

To deal with this troublesome result for human capital, we adjustment human capital stocks by multiplying by the ratio of the country's per capita GDP relative to that of the United States. The logic is that countries might have productivity differences across management teams that can be proxied by the level of development.2

${ }^{2}$ (Trefler $(1993,1995)$ uses this method to adjust for neutral differences in factor productivity in his extension of the Hechscher-Ohlin model. 


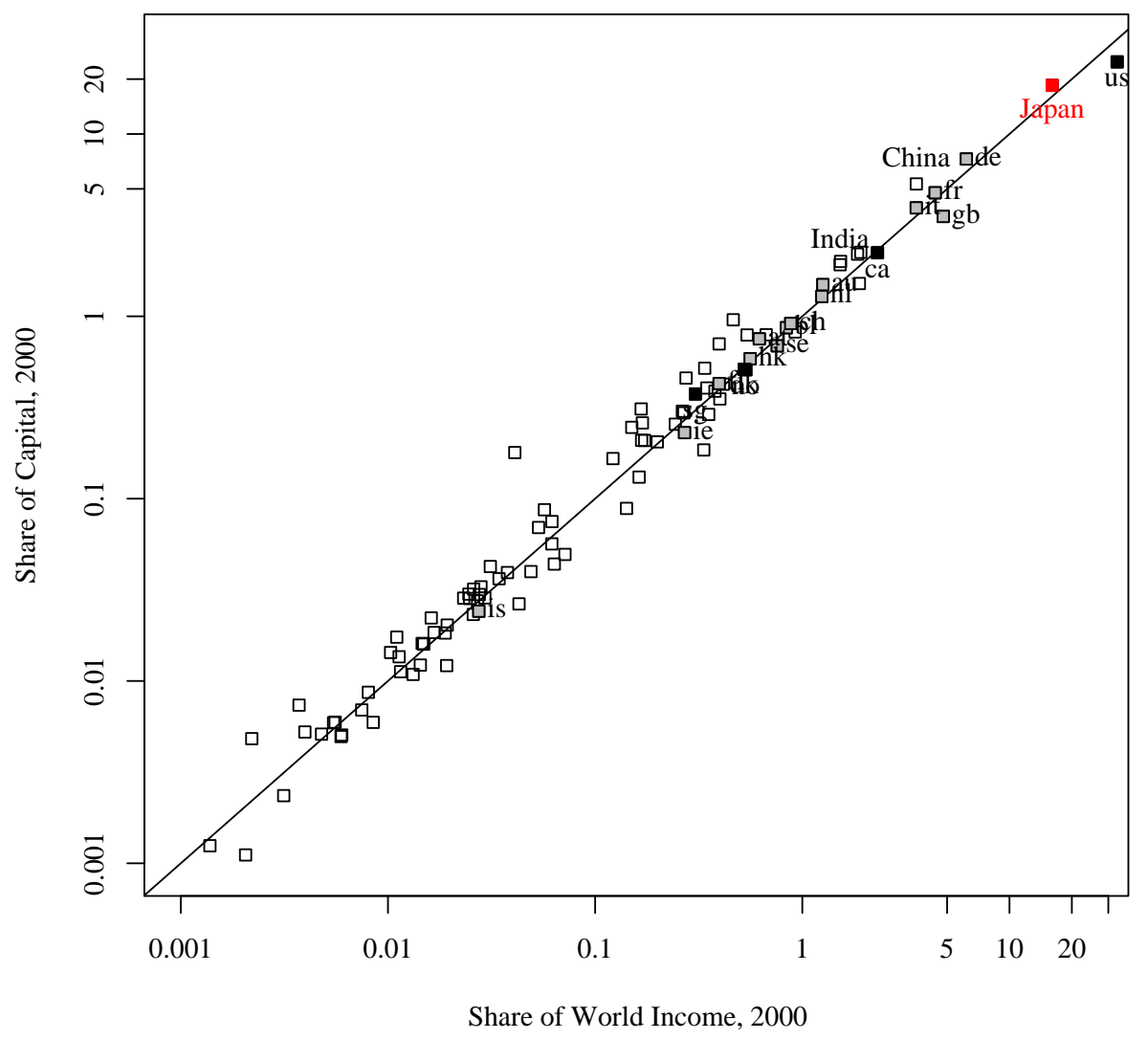

Figure 3: Capital shares versus National Income shares 


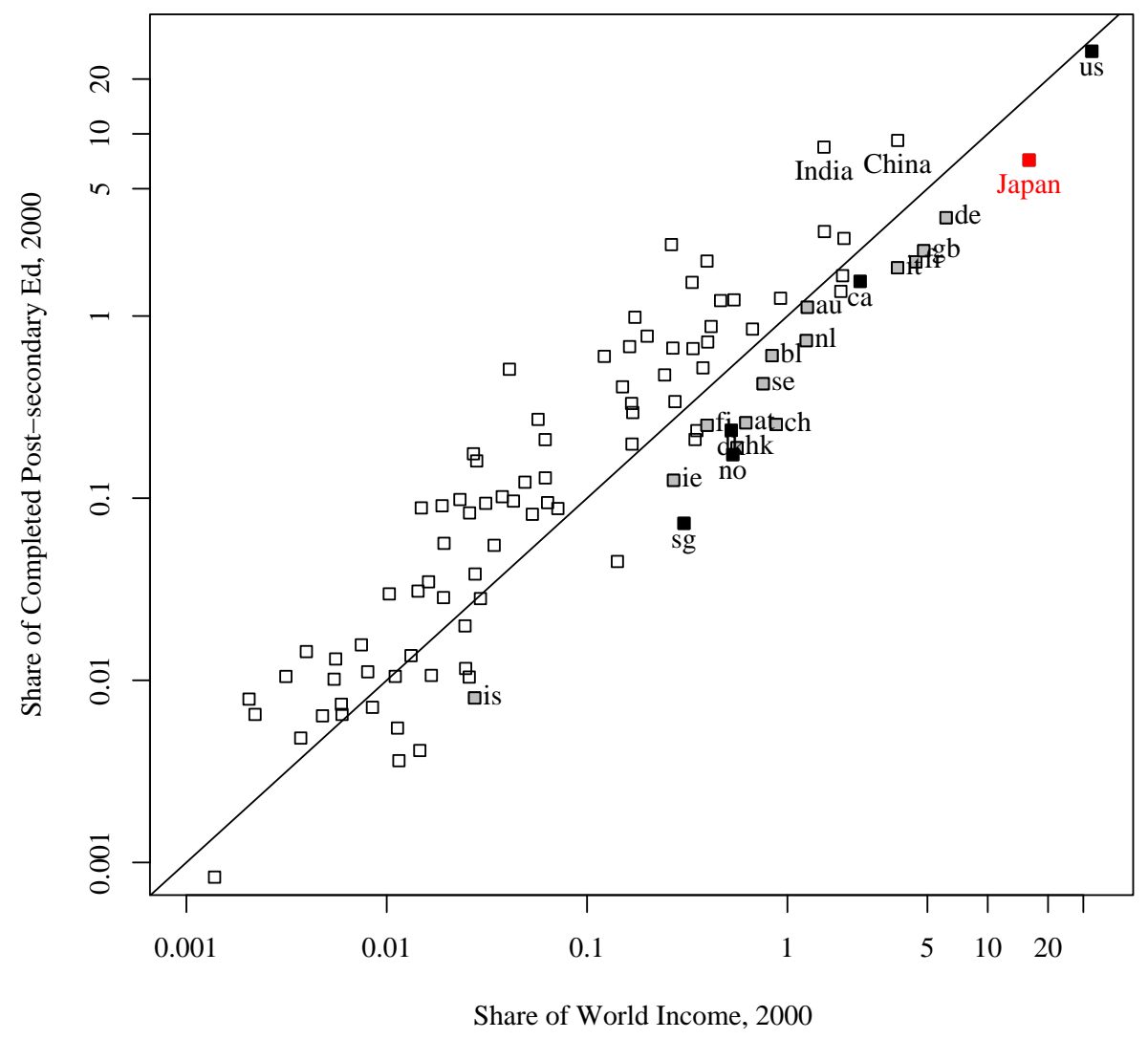

Figure 4: Human Capital shares versus National Income shares 


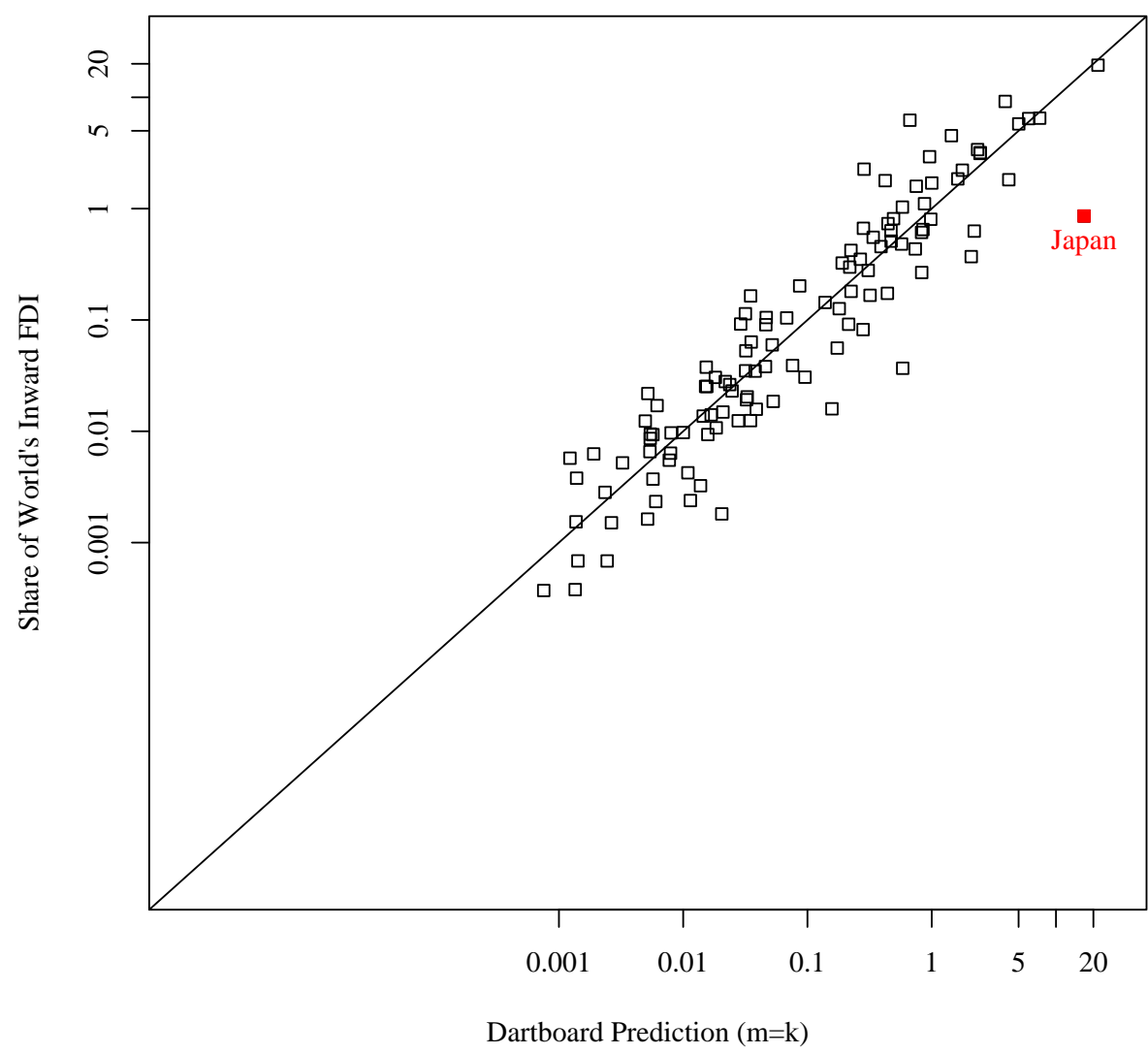

Figure 5: Inward FDI stocks relative to the benchmark, 2002

\section{Results}

Our approach is to use the theoretical model to construct a "benchmark" prediction of each country's share of world FDI and compare its actual FDI to this benchmark. The only unknown parameter is $\theta$ which measures the extent distance reduces the value of a potential acquisition to a bidder. We will assume $\theta=1$ as a base but will also experiment with other values. We will also report results for different proxies for a country's capital stock, $K$, and its number of management teams, $M$. We will report our results using tables of regression results and figures relating actual FDI shares to the benchmark. The human capital data exists only for the years 1980, 1985, 1990, 1995, and 2000. After dropping observations with missing data, we have a sample of roughly 90 countries for each of the five years.

Figure 5 and Figure 6 show the relationship of the benchmark to inward and outward FDI shares for the year 2002 when we use the capital stock to proxy for shares of capital and management teams. The benchmark does a pretty good of predicting inward shares but not so good at predicting outward shares. In particular, the shares of outward stocks for countries with low capital shares are much lower than predicted. 


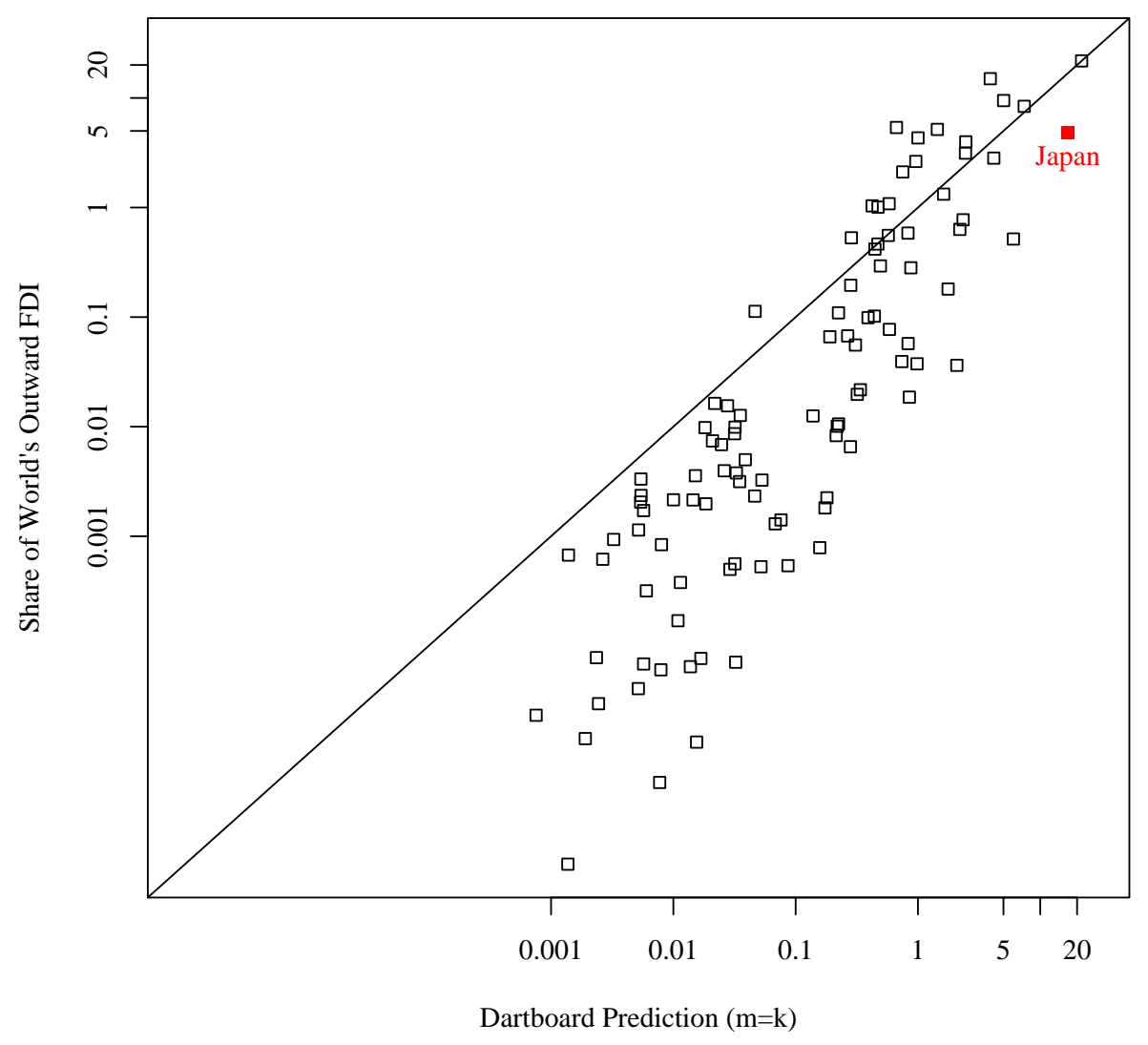

Figure 6: Inward FDI stocks relative to the benchmark, 2002 
Table 1: Outward FDI

\begin{tabular}{lccccc}
\hline \hline Capital & GNI & $\mathrm{K}$ & $\mathrm{K}$ & $\mathrm{K}$ & $\mathrm{K}$ \\
Mgmt teams & $\mathrm{K}$ & GNI & post-sec & hcap & hcap*pcgdpK \\
Distance Cost & $\theta=0$ & $\theta=1$ & $\theta=1$ & $\theta=1$ & $\theta=1$ \\
BENCH & & & & & \\
JAPAN & & & & & \\
RMSE & & & & & \\
$R^{2}$ & & & & \\
OBS & & & & \\
\hline \hline Note:
\end{tabular}

Table 2: Inward FDI

\begin{tabular}{lccccc}
\hline \hline Capital & GNI & K & K & K & K \\
Mgmt teams & GNI & GNI & post-sec & hcap & hcap*pcgdpK \\
Distance Cost & $\theta=0$ & $\theta=1$ & $\theta=1$ & $\theta=1$ & $\theta=1$ \\
BENCH & & & & & \\
JAPAN & & & & & \\
RMSE & & & & & \\
$R^{2}$ & & & & & \\
OBS & & & & & \\
\hline \hline
\end{tabular}

Note:

Tables 1 and 2 will report the regression results that will indicate how well different specifications fit the data. The top three rows of each table indicate the measures of $K$ and $M$ we employ in a particular specification as well as the assumed value for $\theta$. In the following rows we report the coefficients on the benchmark term as well as a Japan dummy capturing the average deviation of Japanese FDI shares from the benchmark. We expect that the coefficient on the benchmark term to equal one. Since the errors term for a given country in different years are likely to be correlated, we use Stata's robust cluster command to compute the standard errors. Hopefully, we will be able to complete this table for the March 13 pre-conference.

That is all for now. More to come. Stay tuned please.

\section{References}

Deardoff, Alan, 1998, "Determinants of Bilateral Trade: Does Gravity Work in a Neoclassical World?" in Frankel ed. The Regionalization of the World Economy.

Eaton, John and Akiko Tamura, 1994, "Bilateralism and Regionalism in Japanese and U.S. Trade and Direct Foreign Investment Patterns," Journal of the Japanese and International Economies, 8, 478-510.

Eaton, John and Akiko Tamura, 1996, "Japanese and US Exports and Investment 
as Conduits of Growth," in Ito, Takatoshi and Anne O. Kruger, eds., Financial Deregulation and Integration in East Asia, Chicago: University of Chicago Press, 1996, pp. 51-72.

Easterly, William and Ross Levine, "It's Not Factor Accumulation: Stylized Facts and Growth Models" The World Bank Economic Review, VOL. 15, NO. 2, 177-219.

Ellison, Glenn and Glaeser, Edward, (1997), "Geographic Concentration in U.S. Manufacturing Industries: a Dartboard Approach," Journal of Political Economy 105(5):889927.

Fukao, Kyoji and Tomofumi Amano, 2003, Inward FDI and the Japanese Economu, Hitotsubashi University manuscript.

Hall and Jones, 1999, "Why are some countries so much more productive than others?" Quarterly Journal of Economics

Harrigan, James and Rohit Vanjani, 2003 "Is Japan's trade (still) different?" Journal of the Japanese and International Economies, 17, 507-519.

Head, Keith, John Ries and Barbara J. Spencer, 2004, "Vertical Networks and U.S. Auto Parts Exports: Is Japan Different?," Journal of Economics 85 Management Strategy, forthcoming and NBER Working Paper, No. 9162 (2002).

Jensen, Michael C. and Richard S. Ruback, "The market for corporate control: The scientific evidence," Journal of Financial Economics Volume 11, Issues 1-4 , April 1983, Pages 5-50.

Saxonhouse, Gary C., 1993, "What Does Japanese Trade Structure Tell Us About Japanese Trade Policy," Journal of Economic Perspectives, 7(3), 21-43.

Trefler, Daniel, 1995, "The Case of the Missing Trade and Other Mysteries," American Economic Review, 85: 1029-1046.

Trefler, Daniel, 1993, "Leontieff was right!" Journal of Political Economy. 